\title{
Upper airway · 1: Allergic rhinitis and asthma: united disease through epithelial cells
}

\author{
A Bourdin, ${ }^{1}$ D Gras, ${ }^{2}$ I Vachier, ${ }^{1}$ P Chanez ${ }^{2}$
}

\begin{abstract}
See Editorial, p 923
${ }^{1}$ Department of Respiratory Disease, CHU Arnaud de Villeneuve, Montpellier, France;

${ }^{2}$ Service de PneumoAllergologie et Laboratoire d'Immunologie, INSERM U 600, Université de la Méditerranée,

Marseille, France
\end{abstract}

Correspondence to: Professor P Chanez, Université de la Méditerranée, AP-HM, 270 Boulevard de Sainte-Marguerite, F-13009 Marseille, France; pascal.chanez@univmed.fr

Received 11 May 2009 Accepted 14 June 2009

\section{ABSTRACT}

The relationship between allergic rhinitis and asthma is now established, and most of the clinical, epidemiological and biological data recommend integrated management. Epithelial cells represent the first barrier of the upper and lower respiratory tracts and thus are logical targets for a comprehensive integrated therapeutic approach. This review discusses rhinosinusitis as a co-morbid condition, a precipitating or triggering condition, and an epiphenomenon as an integrated part of the disease. A better understanding and a more pragmatic method of diagnosis and management is needed using cost-effective longterm strategies.

Rhinitis and asthma have been evaluated and treated as separate disorders, but recent advances in the understanding and knowledge of the underlying processes have moved current opinion towards the concept of unifying the management of these disorders. The "united airway disease hypothesis" proposes that upper and lower airway diseases are both manifestations of a single inflammatory process. ${ }^{1}$ The upper and lower airways interface more than the air and the blood but regulate most of the human body interactions within its environment. Living an entire life with a clean and silent two-step air filter which is not replaceable suggests abilities of plasticity, regulation, teaching, renewal and local to systemic control functions. Adaptive and innate immune systems play a major role in these functions, which are centrally orchestrated within the epithelial barrier. $^{2}$

\section{EPIDEMIOLOGICAL AND CLINICAL ASPECTS}

The prevalence of asthma and rhinitis is increasing worldwide. Environmental factors are mostly thought to be responsible. Both diseases frequently coexist in the same patients, with asthma present in $20-50 \%$ of patients with allergic rhinitis and rhinitis present in up to $80 \%$ of patients with asthma. ${ }^{3-5}$ These data are highly dependent on the way the conditions are defined. ${ }^{1}$ Whether allergic rhinitis precedes asthma, triggers asthma or precipitates asthma are intuitive aspects that require supportive data. The atopic status plays a potentially prominent role in this relationship, but this is not a prerequisite. In a large European cohort, rhinitis was found to be an independent risk factor for asthma, not only in atopic subjects ( $n=1461$, odds ratio (OR) 8.1 (95\% confidence interval (CI) 5.4 to 12.1)) but also in non-atopic subjects $(\mathrm{n}=5198, \quad$ OR $11.6(95 \%$ CI 6.2 to 21.9$)){ }^{6}$ Challenging the nose with allergens will induce the influx of inflammatory cells in the lower airways and vice versa. ${ }^{7}$ Treating the nose will probably, in different ways, affect lower airway inflammation. ${ }^{9}$

\section{DEFINITIONS AND CLINICAL ASPECTS OF ASTHMA}

Asthma is defined as a chronic inflammatory disorder of the airways in which many cells and cellular elements play a role-in particular, mast cells, eosinophils, T cells, macrophages, neutrophils and epithelial cells. In susceptible individuals this inflammation causes recurrent episodes of wheezing, breathlessness, chest tightness and coughing, especially at night or early morning. These episodes are usually associated with widespread but variable airflow obstruction that is often reversible, either spontaneously or with treatment. The inflammation also causes an associated increase in existing bronchial hyper-responsiveness to a variety of stimuli. ${ }^{10}$

The fact that the definition of such a prevalent disease is complex and refers to both physiopathological key concepts as well as clinical features is important. Given the complexity of epidemiological studies to establish a causal link between two diseases such as rhinitis and asthma, it is difficult to determine whether any patient in such a study would comply with the whole definition.

In clinical practice a widespread clinical spectrum is commonly seen, as well as many comorbidities, confounding and/or precipitating conditions including atopy, rhinosinusitis, gastrooesophageal reflux, aspirin intolerance, exposure to cigarette smoke and occupation-related exposures. ${ }^{11}$ In this review, rhinosinusitis will be discussed as a co-morbid condition, a precipitating or triggering condition, and as an epiphenomenon as an integrated part of the disease.

Current guidelines attempt to base the management of asthma on achieving control, when previous guidelines were built on a complex stepby-step management according to clinical severity. This management is closer to the real world and will perhaps provide room for improvement in the overall control of the disease worldwide.

Non-specific bronchial hyper-responsiveness is a common finding in patients with rhinitis, even though asthma symptoms may initially be lacking. Asthma control refers to brief asthma symptoms and the absence of exacerbations. Exacerbations of asthma are events requiring unscheduled visits to healthcare providers and an important change in pharmacological management-usually a short course of oral corticosteroids. The permanent absence of control, recurrent exacerbations and high medication requirements despite optimal 
management define "difficult asthma". This should be investigated using step-by-step investigations to secure the diagnosis of asthma, assess compliance issues and co-morbidities and, in some cases, will lead to the diagnosis of severe asthma. ${ }^{11}$ In these situations the role of rhinosinusitis should be carefully reassessed using clinical and imaging investigations. Rhinosinusitis is frequent and extensive in severe asthma. ${ }^{12}$ It has been shown that ethmoidal involvement is a specific feature of severe asthma, and a relationship has been found between extensive sinusitis and airway inflammation and indirect indices of distal airway changes. ${ }^{13}$

\section{DEFINITION AND CLINICAL ASPECTS OF RHINOSINUSITIS}

Rhinitis is defined as inflammation of the nasal mucosa characterised by nasal discharge, blockage, sneezing and itching, with two or more symptoms occurring for more than $1 \mathrm{~h}$ on most days. It can be further classified as intermittent (symptoms occurring on $<4$ days out of 7 or for $<4$ weeks per year) or persistent (symptoms occurring on at least 4 days out of 7 or for $>4$ weeks per year). ${ }^{14}{ }^{15}$ The impact of chronic rhinitis on sleep, daily activities, work or school is a major determinant of impairment of quality of life in patients with asthma. ${ }^{3}$ As mentioned above, there is a significant relationship between the severity of sinus involvement and asthma severity. ${ }^{12}$ This could be related to a high level of systemic inflammation in patients with severe asthma. The perception of nasal symptoms is highly variable. This fact has been illustrated in patients with chronic obstructive pulmonary disease in whom a discrepancy has been found between nasal inflammation and symptoms. ${ }^{16}$ From a clinical point of view, it is therefore unsatisfactory to rely completely on the report of symptoms by patients as the only way of assessing rhinosinusitis. ${ }^{17}$

It is worth establishing a comprehensive biological pathway that will unify the upper and lower airways to support the epidemiological and clinical interpolations summarised above. This will lead to the development of new ways to assess the whole airway tree using non-invasive biomarkers.

\section{EFFECTS OF ANTI-INFLAMMATORY TREATMENT}

Intranasal corticosteroids and antihistamines (intranasal or oral) have been shown to have anti-inflammatory effects on different aspects of inflammation in allergic rhinitis. ${ }^{18}$ Other potential treatments are intranasal cromones which stabilise mast cells by inhibiting degranulation and release of pro-mediators and newly formed mediators; intranasal anticholinergic therapy which provides relief only for excessive rhinorrhoea; and leukotriene antagonists which block the cysteinyl leukotriene receptor. ${ }^{19} 20$

In patients with asthma, inhalation of corticosteroids reduces bronchial inflammation by days or weeks, whereas reductions in airway remodelling features are reported after about 1 year. ${ }^{21}$ The clinical benefits of early treatment with anti-inflammatory treatment for asthma have been shown. ${ }^{22}$ It has been reported that the treatment of the nose may affect symptoms of asthma and bronchial hyper-responsiveness in mild allergic asthma. In some studies the use of nasal steroids was reported to be of equal value to low doses of bronchial steroids. However, asthma and rhinitis have been treated as separate diseases, but most of the current national and international recommendations (GINA, ARIA, ANAES) suggest a combined approach or at least the treatment of rhinitis as a co-morbid condition in asthma. A managed care study that included children with asthma and co-morbid rhinitis, sinusitis or otitis media showed that treatment directed at the upper airways was associated with a 30\% reduction in asthma-related visits to the emergency department. ${ }^{23}{ }^{24}$ Observational data in adults suggest that prescribing a treatment to control rhinosinusitis symptoms may lead to a better control of asthma and a subsequent reduction in exacerbations. ${ }^{25}$ The consequences are not only theoretical, but are important for diagnostic and therapeutic purposes. ${ }^{26}$ In patients with severe asthma with extensive pansinusitis, clinical reports have shown that surgical ethmoidectomy is of benefit but a placebo controlled study is difficult to undertake in this situation.

\section{PATHOLOGICAL ASPECTS}

\section{Differences and similarities between nasal and bronchial mucosa}

While the nasal and bronchial mucosa have some evident similarities such as a pseudostratified epithelium and the presence of both ciliated and columnar cells resting on a basement membrane, differences are mainly seen at the submucosal level (fig 1). The large highly developed vasculature of the nose contrasts with the smooth muscle bundles that surround the bronchial airways. ${ }^{1}$ Whether inflammationinduced differential symptoms represent the expression of these anatomical discrepancies needs to be established.

Tight junctions, peptidases and a large antioxidant apparatus are key features of the anatomical barrier of the nasal epithelium. Epithelial and endothelial permeability to small molecules $(<1000 \mathrm{Da})$ in the nose is likely to produce plasma concentrations of medications close to direct intravenous administration. The mucosal associated lymphoid tissue is more developed in the nose than in the bronchi.

In asthma, epithelial fragility is a common finding while basement membrane thickness is related to the severity of the condition. In a study comparing the nose and bronchi of the same patients, eosinophilia, epithelial shedding and basement membrane thickness were similar in controls and steroiddependent patients with asthma, while these features were more pronounced in untreated patients with mild asthma at the bronchial level (figs 2 and 3). Enhanced abilities of regeneration and protection present in the nose support the hypothesis that the nasal mucosa should be more resistant to inflammation and able to withstand environmental injuries on a near-constant basis without scarring. ${ }^{27} 28$

Inflammatory changes seen in the nasal mucosa are closely related to those observed at the bronchial level. The same patterns of inflammatory cells such as eosinophils, mast cells, $T$ cells and macrophages are found. ${ }^{29}{ }^{30}$ Similar chemokines and cytokines are expressed at both sites, including eotaxin, interleukin 5 (IL5), RANTES, IL4, IL13 and granulocyte-macrophage colony stimulating factor (GM-CSF). ${ }^{78}$ Most of these molecules trigger a mainly local eosinophilic inflammatory process (fig 4).

These observations support the unified airway hypothesis as the structural and inflammatory changes-both static and also dynamic after challenges-are more or less similar.

Epithelial cells are crucially situated at the external-internal milieu interface and will perform most of the actions cited above-plasticity, regulation, regeneration, orchestration of the inflammatory process and structural changes-by the production of cytokines, chemokines and other molecules balancing the inflammatory process.

\section{EPITHELIAL CELLS}

The airway tree is complex and cell populations vary systematically both by airway generation and by species. In human 
Figure 1 (a) Nasal and (b) bronchial biopsies obtained from the same patient with mild asthma showing CD8 T lymphocyte immunoreactivity of nasal and bronchial biopsies, epithelial columnar cells, epithelial shedding and basement membrane (personal unpublished data). Original magnification $\times 400$.
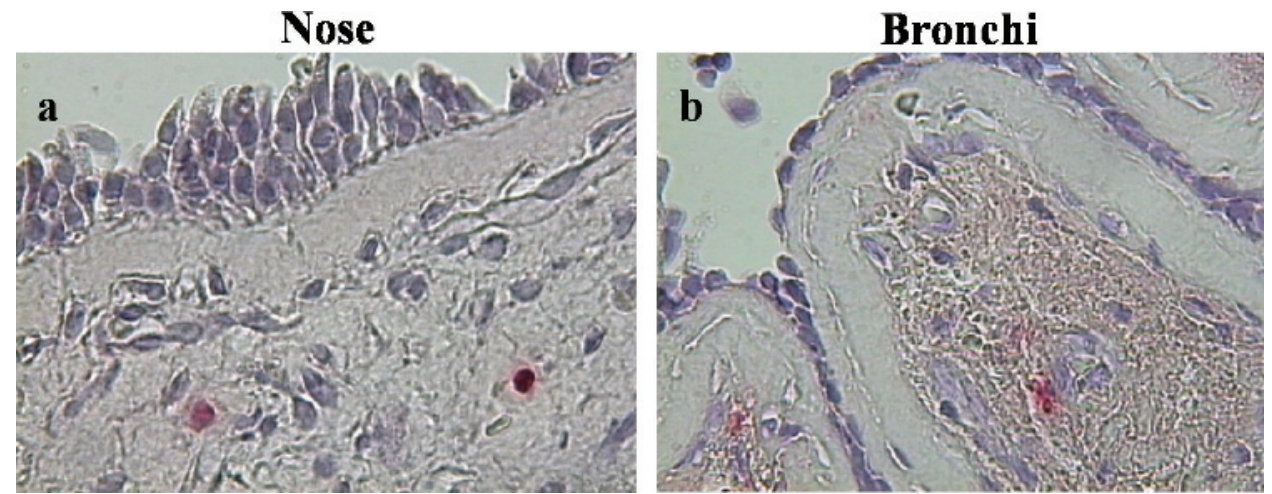

upper airways the epithelium is pseudostratified, prismatic and ciliated, and separated from the underlying chorion by a basal membrane as in the proximal level of the lower airways. Indeed, in the large airways of the lower respiratory tract, the major cell types are ciliated, undifferentiated columnar, secretory and basal cells and also a number of less common cell types such as cartilage cells, mucus glands and neuroendocrine cells. In the small airways the cell types are similar, with relatively more ciliated cells and the secretory cells shift to the Clara cell type. At the distal level the airway epithelium merges with the alveolar epithelium, with type I and type II cells. ${ }^{31}$ The airway epithelium acts as a barrier protecting the lung from inhaled substances. Indeed, the epithelium is the point of first contact for breathable particles, respiratory viruses and airborne allergens and, as such, constitutes the interface between the external environment and the internal milieu of the lung. Under normal circumstances the epithelium forms a highly regulated and almost impermeable barrier through the formation of tight junctions. ${ }^{32}{ }^{33}$ It also serves to regulate airway surface liquid volume and composition, mucus secretion and cilia beat to maintain a sterile lung through effective mucociliary clearance. In addition to its classic barrier function in response to harmful substances, the bronchial epithelium modulates immune and inflammatory responses by releasing pro- or anti-inflammatory mediators.

\section{Mediator functions of epithelial cells}

The epithelium can generate a range of products but, specifically, the synthesis and release of mediators involved in

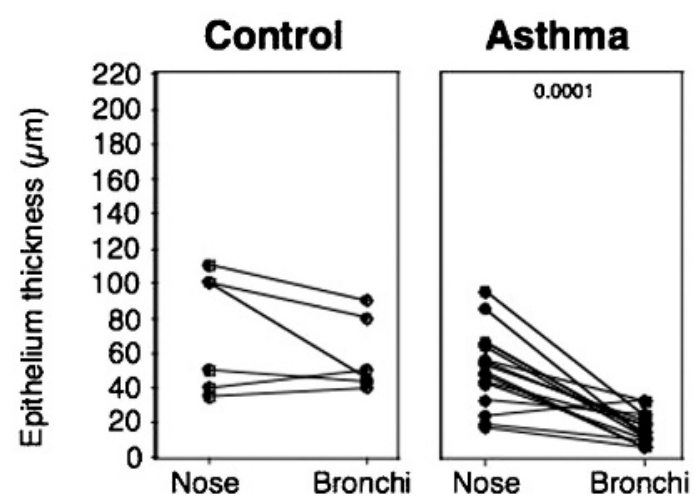

Figure 2 Epithelial thickness of nasal and bronchial biopsies obtained from controls $(n=6)$ and patients with mild asthma $(n=16)$. Epithelial thickness is decreased (epithelial shedding increased) in the bronchi compared with the nose in the patients with asthma (personal unpublished data); $p<0.001$ (Wilcoxon test). the attraction and activation of cells to the site of inflammation represents an important process in allergic mucosal inflammation and in asthma.

In nasal biopsy samples from patients with seasonal allergic rhinitis there is an increased expression of intercellular adhesion molecule $1 . .^{34}$ In the same way, enhanced expression of IL6, tumour necrosis factor $\alpha$ (TNF $\alpha$ ), IL-8, GM-CSF and RANTES (CCL5) has been demonstrated within the airway epithelium in nasal biopsies taken from individuals with perennial allergic rhinitis. ${ }^{35}$ Eotaxin (CCL11), a chemokine also released by epithelial cells, is upregulated in the nasal tissue of patients with acute allergic rhinitis, ${ }^{36}$ and nasal challenge with eotaxin has been found to induce nasal eosinophilic inflammation. GMCSF and stem cell factor (SCF), both generated by epithelial cells, promote survival of inflammatory cells in situ, particularly eosinophils and mast cells. Cultured nasal epithelial cells have been shown to generate SCF in vitro, and elevated levels of SCF have been found in nasal lavage fluid in patients with seasonal allergic rhinitis $^{37}$ and correlated with nasal lavage mast cell chemotactic activity.

In the same way, the airway epithelium in patients with asthma is a major source of cytokines and chemokines that are strongly implicated in maintaining asthmatic inflammation, including IL8, TNF $\alpha$, GM-CSF, IL5, RANTES (CCL5), eotaxin (CCL11), macrophage chemotactic peptides or thymic stromal lymphopoietin (TSLP). For example, TSLP is generated in large amounts by airway epithelial cells in response to selective toll-like
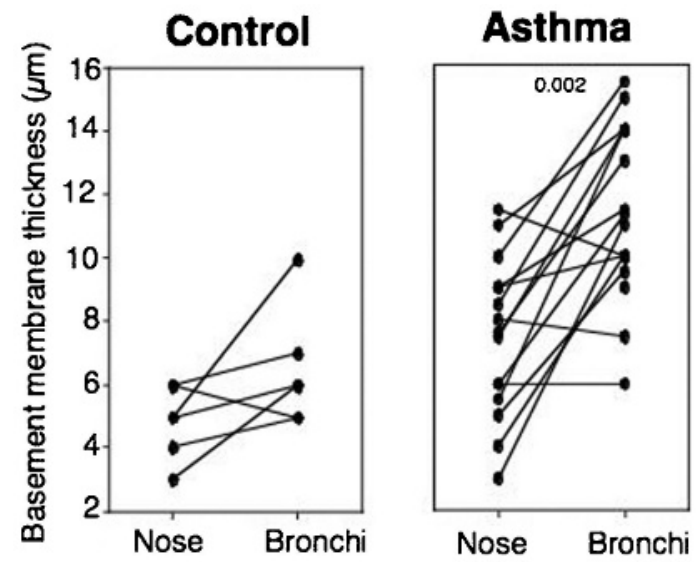

Figure 3 Basement membrane thickness of nasal and bronchial biopsies obtained from controls $(n=6)$ and patients with mild asthma $(\mathrm{n}=16)$. Epithelial thickness is increased in the bronchi compared with the nose in the patients with asthma (personal unpublished data); $p=0.002$ (Wilcoxon test). 


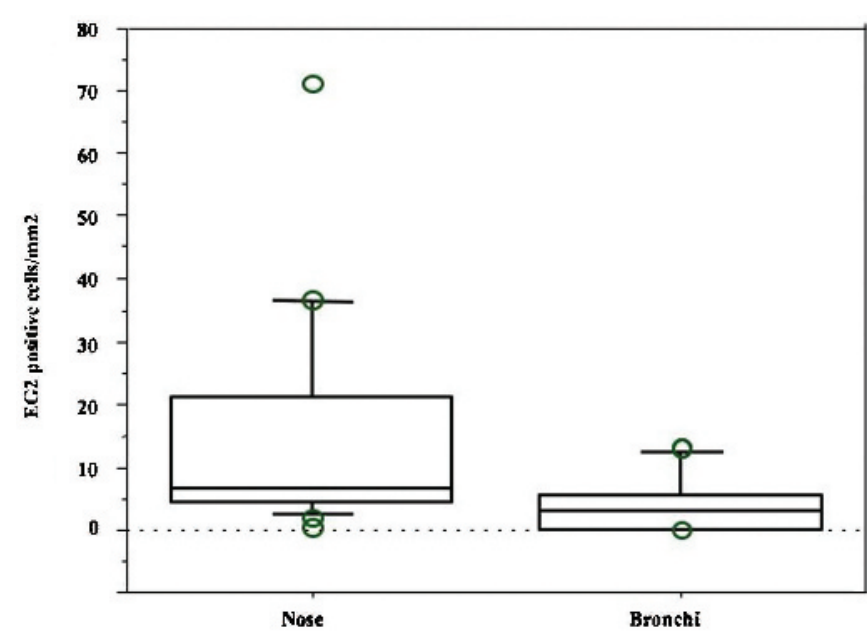

Figure 4 Eosinophil number assessed as EG2 positive cells in nasal and bronchial biopsies of patients with mild asthma. The number of eosinophils in the bronchi is decreased compared with the nose in the patients with asthma $(n=16)(p=0.01$, Wilcoxon test) whereas no eosinophils were found in control subjects (personal unpublished data).

receptor stimulation and shows the ability of the epithelium to provide a microenvironment sustaining ongoing Th2-like inflammation. ${ }^{38}$

\section{Regulation of mucus secretion}

The airway epithelium is also implicated in the regulation of mucus secretion by both goblet cells of the epithelial lining and mucous cells of the submucosal glands. Hypersecretion of mucus, driven by microbial factors and innate and adaptive immunity, is an integral component of the immune response to pathogens. These hypersecretory responses are seen in diseases such as asthma and allergic rhinitis and appear to be a major contributor to the severity of the condition. Indeed, in these chronic inflammatory airway diseases there is enlargement of the submucosal glands and increased numbers of goblet cells in the airway surface epithelium and their presence in the distal airways where they do not normally occur. ${ }^{39}{ }^{40}$ Animal models and some human studies have described factors that contribute to goblet cell metaplasia. It is suggested that an increase in IL4 and/or IL13 participates in the process through differentiation of ciliated epithelial cells into a goblet cell/mucus-producing epithelium characteristic of Th2-mediated inflammation. ${ }^{41-43}$ Activation of epidermal growth factor receptors (EGFRs) on epithelial cells during repair by transforming growth factor $\alpha$ $(\mathrm{TGF} \alpha)$ is also involved in goblet cell metaplasia. ${ }^{44}$ Finally, through activation of dual oxidase 1 (Duox1), reactive oxygen species generated by epithelial damage stimulate TGF $\alpha$ cleavage from its membrane precursor to promote mucus metaplasia. ${ }^{45}$ The major constituents of mucus are the mucin glycoproteins and, of the identified mucin genes (MUCs), expression of the secreted mucin MUC5AC is increased in asthmatic epithelial cells, ${ }^{46}{ }^{47}$ contributing to the viscous mucus characteristic of asthma. ${ }^{48}$ At the genetic level, four highly polymorphic genes (MUC6, MUC2, MUC5AC and MUC5B) which encode gelforming mucins play a role. ${ }^{49}$ Moreover, IL4, IL9 and IL13 induce selective mucin expression in airway epithelial cells and also the calcium-activated chloride channel 1 (hCLC A1; Gob 5), which is itself involved in regulating the expression of gel-forming mucins. ${ }^{50} \mathrm{~A}$ recent study has shown expression of nerve growth factor (NGF) in the cytoplasm of mucous cells and in a few cells of the basal layer in the nasal mucosa, ${ }^{51}$ as has been shown in the bronchi. ${ }^{52}$ Bresciani et $a^{51}$ speculate that NGF produced and released in epithelial and glandular structures of the airways may play a critical role-possibly via tachykinin release-in mucus hypersecretion, a typical sign of allergic inflammation of the airways which occurs in both asthma and rhinitis. An in vitro study showed that NGF induces MUC5AC overexpression in epithelial cell lines and, similarly, a mouse model overexpressing NGF in Clara cells showed goblet cell hyperplasia and MUC5AC overexpression.

\section{Epithelial damage in asthma and rhinitis}

The airway epithelium of patients with asthma is largely abnormal, with evidence of fragility and goblet cell hyperplasia and metaplasia. This fragility is not only limited to the lower airways, since disrupted desmosome formation has also been shown in nasal polyps from patients with asthma. ${ }^{53}$ Moreover, this epithelium is also more susceptible to oxidant injury and apoptosis than normal epithelium, ${ }^{545}$ and it is becoming apparent that normal repair processes in the asthmatic epithelium are also compromised. Indeed, during epithelial surface injury the normal response is to upregulate receptors, notably EGFR, to drive proliferation and repair. ${ }^{56}$ However, the expression of the EGFR is increased in the asthmatic epithelium-especially in areas where columnar cells have been shed, ${ }^{57}$ but also in areas of intact epithelium-and does not correlate with the proliferative response of repairing cells. ${ }^{58}$ Furthermore, several pro-inflammatory transcription factors such as nuclear factor- $\mathrm{\kappa B}$, activator protein-1, signal transducer and activator of transcription 1 (STAT1) and STAT6 or heat-shock proteins are unnaturally expressed in the epithelium of patients with asthma ${ }^{59-61}$ In allergic rhinitis the epithelial cells become activated and an accumulation of mast cells, eosinophils and basophils occurs within the airway epithelium in addition to eosinophil accumulation within the deeper lamina propria. ${ }^{35}$ In patients with allergic rhinitis without asthma, inflammatory cells and mediators have been found in the lower airways, although there is no apparent clinical manifestation of lower airway inflammation. ${ }^{82}$ Likewise, in the upper airways of patients with asthma, an eosinophilic infiltration has been demonstrated even in the absence of rhinitis. ${ }^{30}$

\section{RESOLUTION OF AIRWAY INFLAMMATION}

As epithelial cells have pivotal regulatory roles in inflammation and host defence against pathogens, it is also of interest to elucidate regulatory signals that could physiologically attenuate activation of epithelial and inflammatory cells both in asthma and rhinitis.

Lipoxins are lipid mediators locally produced via cell-cell interactions between leukocytes and resident cells during inflammation in human tissues to prevent an over-exuberant inflammatory response and limit damage to the host. ${ }^{63}$ In vitro and in vivo studies have shown that lipoxins display diverse potent anti-inflammatory actions including regulation of human bronchial epithelial cell function after injury to limit proinflammatory responses and promote a return to homeostasis. ${ }^{64}$

Lipoxin A4 (LXA4) exerts its biological actions through its specific high affinity $G$ protein-coupled receptor, formyl-peptide receptor like-1 (FPRL-1) or ALX. ${ }^{65}$ This receptor is widely expressed in the epithelium in human proximal endobronchial biopsies ${ }^{66}$ Lipoxins are "stop signals" for airway inflammation, acting directly on epithelial cells via interaction with its cognate receptor FPRL-1. We can postulate that upregulation of the lipoxin signalling circuits would facilitate restitution of airway 
epithelial homeostasis and subsequent potential resolution of inflammation, not only in asthma but also in rhinitis, and this represents a potential new therapeutic approach.

\section{CONCLUSION}

The relationship between allergic rhinitis and asthma is now established. Most of the clinical, epidemiological and biological data recommend integrated management. Epithelial cells represent the first barrier of the upper and lower respiratory tracts and thus are logical targets for a comprehensive integrated therapeutic approach. These diseases impact on the patient's quality of life and are a financial burden for our healthcare systems. A better understanding and a more pragmatic method of diagnosis and management is needed using cost-effective long-term strategies.

Competing interests: None.

Provenance and peer review: Commissioned; not externally peer reviewed.

\section{REFERENCES}

1. Togias A. Rhinitis and asthma: evidence for respiratory system integration. J Allergy Clin Immunol 2003;111:1171-84.

2. Chanez P. Severe asthma is an epithelial disease. Eur Respir J 2005;25:945-6.

3. Demoly $\mathbf{P}$, Bousquet J. The relation between asthma and allergic rhinitis. Lancet 2006;368:711-3

4. Guerra S, Sherrill DL, Martinez FD, et al. Rhinitis as an independent risk factor for adult-onset asthma. J Allergy Clin Immunol 2002;109:419-25

5. Shaaban R, Zureik M, Soussan D, et al. Rhinitis and onset of asthma: a longitudinal population-based study. Lancet 2008;372:1049-57.

6. Leynaert B, Bousquet J, Neukirch C, et al. Perennial rhinitis: an independent risk factor for asthma in nonatopic subjects: results from the European Community Respiratory Health Survey. J Allergy Clin Immunol 1999;104:301-4.

7. Braunstahl GJ, Overbeek SE, Fokkens WJ, et al. Segmental bronchoprovocation in allergic rhinitis patients affects mast cell and basophil numbers in nasal and bronchial mucosa. Am J Respir Crit Care Med 2001;164:858-65.

8. Braunstahl GJ, Overbeek SE, Kleinjan A, et al. Nasal allergen provocation induces adhesion molecule expression and tissue eosinophilia in upper and lower airways. $J$ Allergy Clin Immunol 2001;107:469-76.

9. Lipworth BJ, White PS. Allergic inflammation in the unified airway: start with the nose. Thorax 2000;55:878-81.

10. Bateman ED, Hurd SS, Barnes PJ, et al. Global strategy for asthma management and prevention: GINA executive summary. Eur Respir J 2008;31:143-78.

11. Chanez $\mathbf{P}$, Wenzel SE, Anderson GP, et al. Severe asthma in adults: what are the important questions? J Allergy Clin Immunol 2007:119:1337-48.

12. Bresciani M, Paradis L, Des Roches A, et al. Rhinosinusitis in severe asthma. J Allergy Clin Immunol 2001;107:73-80.

13. ten Brinke A, Grootendorst DC, Schmidt JT, et al. Chronic sinusitis in severe asthma is related to sputum eosinophilia. J Allergy Clin Immunol 2002;109:621-6.

14. Bousquet PJ, Bousquet-Rouanet L, Co Minh HB, et al. ARIA (Allergic Rhinitis and its Impact on Asthma) classification of allergic rhinitis severity in clinical practice in France. Int Arch Allergy Immunol 2007;143:163-9.

15. Passalacqua G, Bousquet PJ, Carlsen KH, et al. ARIA update: I-Systematic review of complementary and alternative medicine for rhinitis and asthma. J Allergy Clin Immunol 2006;117:1054-62.

16. Vachier I, Vignola AM, Chiappara G, et al. Inflammatory features of nasal mucosa in smokers with and without COPD. Thorax 2004;59:303-7.

17. Raherison C, Montaudon M, Stoll D, et al. How should nasal symptoms be investigated in asthma? A comparison of radiologic and endoscopic findings. Allergy 2004;59:821-6.

18. Carr WW, Nelson MR, Hadley JA. Managing rhinitis: strategies for improved patient outcomes. Allergy Asthma Proc 2008;29:349-57.

19. van Cauwenberge $\mathbf{P}$, Bachert $C$, Passalacqua $\mathrm{G}$, et al. Consensus statement on the treatment of allergic rhinitis. European Academy of Allergology and Clinical Immunology. Allergy 2000;55:116-34

20. Bachert C, van Cauwenberge P, Khaltaev N. Allergic rhinitis and its impact on asthma. In collaboration with the World Health Organization. Executive summary of the Workshop Report. 7-10 December 1999, Geneva, Switzerland. Allergy 2002; 57:841-55.

21. Ward C, Pais M, Bish R, et al. Airway inflammation, basement membrane thickening and bronchial hyperresponsiveness in asthma. Thorax 2002;57:309-16.

22. Haahtela T, Jarvinen $\mathrm{M}$, Kava $\mathrm{T}$, et al. Effects of reducing or discontinuing inhaled budesonide in patients with mild asthma. N Engl J Med 1994;331:700-5.

23. Adams RJ, Fuhlbrigge AL, Finkelstein JA, et al. Intranasal steroids and the risk of emergency department visits for asthma. J Allergy Clin Immunol 2002;109:636-42.

24. Bousquet J, Gaugris S, Kocevar VS, et al. Increased risk of asthma attacks and emergency visits among asthma patients with allergic rhinitis: a subgroup analysis of the investigation of montelukast as a partner agent for complementary therapy (corrected). Clin Exp Allergy 2005;35:723-7.

25. Crystal-Peters J, Neslusan C, Crown WH, et al. Treating allergic rhinitis in patients with comorbid asthma: the risk of asthma-related hospitalizations and emergency department visits. J Allergy Clin Immunol 2002;109:57-62.

26. de Benedictis FM, del Giudice MM, Severini S, et al. Rhinitis, sinusitis and asthma: one linked airway disease. Paediatr Respir Rev 2001:2:358-64.

27. Polosa R, Prosperini G, Tomaselli V, et al. Expression of c-erbB receptors and ligands in human nasal epithelium. J Allergy Clin Immunol 2000;106:1124-31.

28. Shaida A, Kenyon G, Devalia J, et al. Matrix metalloproteinases and their inhibitors in the nasal mucosa of patients with perennial allergic rhinitis. J Allergy Clin Immunol 2001;108:791-6.

29. Chanez P, Vignola AM, Vic P, et al. Comparison between nasal and bronchia inflammation in asthmatic and control subjects. Am J Respir Crit Care Med 1999;159:588-95.

30. Gaga M, Lambrou P, Papageorgiou N, et al. Eosinophils are a feature of upper and lower airway pathology in non-atopic asthma, irrespective of the presence of rhinitis. Clin Exp Allergy 2000;30:663-9.

31. Crystal RG, Randell SH, Engelhardt JF, et al. Airway epithelial cells: current concepts and challenges. Proc Am Thorac Soc 2008;5:772-7.

32. Churg A. The uptake of mineral particles by pulmonary epithelial cells. Am J Respir Crit Care Med 1996:154:1124-40.

33. Sparrow MP, Omari TI, Mitchell HW. The epithelial barrier and airway responsiveness. Can J Physiol Pharmacol 1995;73:180-90.

34. Ciprandi G, Pronzato C, Ricca V, et al. Evidence of intercellular adhesion moleculeexpression on nasal epithelial cells in acute rhinoconjunctivitis caused by pollen exposure. J Allergy Clin Immunol 1994:94:738-46.

35. Howarth PH, Salagean M, Dokic D. Allergic rhinitis: not purely a histamine-related disease. Allergy 2000;55(Suppl 64):7-16.

36. Minshall EM, Cameron L, Lavigne $F$, et al. Eotaxin mRNA and protein expression in chronic sinusitis and allergen-induced nasal responses in seasonal allergic rhinitis. Am J Respir Cell Mol Biol 1997;17:683-90.

37. Nilsson G, Hjertson $\mathrm{M}$, Andersson $\mathrm{M}$, et al. Demonstration of mast-cell chemotactic activity in nasal lavage fluid: characterization of one chemotaxin as c-kit ligand, stem cell factor. Allergy 1998;53:874-9.

38. Bals $\mathbf{R}$, Hiemstra PS. Innate immunity in the lung: how epithelial cells fight against respiratory pathogens. Eur Respir J 2004;23:327-33.

39. Martinez-Anton A, Debolos C, Garrido M, et al. Mucin genes have different expression patterns in healthy and diseased upper airway mucosa. Clin Exp Allergy 2006; 36:448-57.

40. Shimura S, Andoh Y, Haraguchi M, et al. Continuity of airway goblet cells and intraluminal mucus in the airways of patients with bronchial asthma. Eur Respir $J$ 1996;9:1395-401.

41. Kondo M, Tamaoki J, Takeyama K, et al. Elimination of IL-13 reverses established goblet cell metaplasia into ciliated epithelia in airway epithelial cell culture. Allergol Int 2006:55:329-36.

42. Kondo M, Tamaoki J, Takeyama K, et al. Interleukin-13 induces goblet cell differentiation in primary cell culture from Guinea pig tracheal epithelium. Am J Respir Cell Mol Biol 2002;27:536-41.

43. Lordan JL, Bucchieri F, Richter A, et al. Cooperative effects of Th2 cytokines and allergen on normal and asthmatic bronchial epithelial cells. J Immunol 2002;169:407-14.

44. Deshmukh HS, Case LM, Wesselkamper SC, et al. Metalloproteinases mediate mucin $5 \mathrm{AC}$ expression by epidermal growth factor receptor activation. Am J Respir Crit Care Med 2005;171:305-14

45. Shao MX, Nadel JA. Dual oxidase 1-dependent MUC5AC mucin expression in cultured human airway epithelial cells. Proc Natl Acad Sci U S A 2005;102:767-72.

46. Fahy JV. Goblet cell and mucin gene abnormalities in asthma. Chest 2002;122(6 Suppl):320-6S.

47. Chu HW, Balzar S, Seedorf GJ, et al. Transforming growth factor-beta2 induces bronchial epithelial mucin expression in asthma. Am J Pathol 2004;165:1097-106.

48. Rose MC, Voynow JA. Respiratory tract mucin genes and mucin glycoproteins in health and disease. Physiol Rev 2006;86:245-78.

49. Rousseau K, Byrne C, Griesinger G, et al. Allelic association and recombination hotspots in the mucin gene (MUC) complex on chromosome 11p15.5. Ann Hum Genet 2007;71:561-9.

50. Holgate ST. Epithelium dysfunction in asthma. J Allergy Clin Immunol 2007:120:1233-6.

51. Bresciani M, Laliberte F, Laliberte MF, et al. Nerve growth factor localization in the nasal mucosa of patients with persistent allergic rhinitis. Allergy 2009;64:112-7.

52. Olgart Hoglund $\mathbf{C}$, de Blay F, Oster JP, et al. Nerve growth factor levels and localisation in human asthmatic bronchi. Eur Respir J 2002;20:1110-6.

53. Shahana S, Jaunmuktane Z, Asplund MS, et al. Ultrastructural investigation of epithelial damage in asthmatic and non-asthmatic nasal polyps. Respir Med 2006; 100:2018-28.

54. Bayram H, Rusznak C, Khair OA, et al. Effect of ozone and nitrogen dioxide on the permeability of bronchial epithelial cell cultures of non-asthmatic and asthmatic subjects. Clin Exp Allergy 2002;32:1285-92.

55. Bucchieri F, Puddicombe SM, Lordan JL, et al. Asthmatic bronchial epithelium is more susceptible to oxidant-induced apoptosis. Am J Respir Cell Mol Biol 2002;27:179-85.

56. Holgate ST, Holloway J, Wilson S, et al. Epithelial-mesenchymal communication in the pathogenesis of chronic asthma. Proc Am Thorac Soc 2004;1:93-8. 
57. Amishima M, Munakata M, Nasuhara $Y$, et al. Expression of epidermal growth factor and epidermal growth factor receptor immunoreactivity in the asthmatic human airway. Am J Respir Crit Care Med 1998;157:1907-12.

58. Puddicombe SM, Polosa R, Richter A, et al. Involvement of the epidermal growth factor receptor in epithelial repair in asthma. Faseb J 2000;14:1362-74.

59. Mullings RE, Wilson SJ, Puddicombe SM, et al. Signal transducer and activator of transcription 6 (STAT-6) expression and function in asthmatic bronchial epithelium. J Allergy Clin Immunol 2001;108:832-8.

60. Sampath D, Castro M, Look DC, et al. Constitutive activation of an epithelial signal transducer and activator of transcription (STAT) pathway in asthma. J Clin Invest 1999;103:1353-61.

61. Holgate ST, Lackie $\mathrm{P}$, Wilson $\mathrm{S}$, et al. Bronchial epithelium as a key regulator of airway allergen sensitization and remodeling in asthma. Am J Respir Crit Care Med 2000;162:S113-7.
62. Foresi A, Leone C, Pelucchi A, et al. Eosinophils, mast cells, and basophils in induced sputum from patients with seasonal allergic rhinitis and perennial asthma: relationship to methacholine responsiveness. J Allergy Clin Immunol 1997:100:58-64.

63. Serhan CN. Lipoxins and aspirin-triggered 15-epi-lipoxins are the first lipid mediators of endogenous anti-inflammation and resolution. Prostaglandins Leukot Essent Fatty Acids 2005;73:141-62.

64. Bonnans C, Fukunaga K, Levy MA, et al. Lipoxin A(4) regulates bronchial epithelial cell responses to acid injury. Am J Pathol 2006;168:1064-72.

65. Chiang N, Arita M, Serhan CN. Anti-inflammatory circuitry: lipoxin, aspirin-triggered lipoxins and their receptor ALX. Prostaglandins Leukot Essent Fatty Acids 2005;73:163-77.

66. Bonnans C, Gras D, Chavis C, et al. Synthesis and anti-inflammatory effect of lipoxins in human airway epithelial cells. Biomed Pharmacother 2007;61:261-7.

\section{Lung alert}

\section{Diarylquinoline TMC207 as potential new therapy for multidrug-resistant tuberculosis}

TMC207 is an investigational diarylquinoline which inhibits mycobacterial ATP synthase in drug-sensitive and drug-resistant Mycobacterium tuberculosis in vitro. It is bactericidal to dormant tubercle bacilli, therefore offering a new mechanism for the treatment of multidrug-resistant tuberculosis.

This study is the first stage of a phase 2 randomised controlled trial. Conducted in South Africa, newly diagnosed patients with pulmonary tuberculosis resistant to both isoniazid and rifampin were randomly assigned to TMC207 or placebo in a double-blind manner in combination with a standard five-drug second-line antituberculosis regime and given over an 8 -week period. The primary end point was the conversion of sputum cultures from positive to negative; the study also collected further pharmacokinetic, safety and adverse event data.

Of the initial 47 patients (predominantly HIV-negative black men with a median age of 33 years), 41 completed the 8-week course. The addition of TMC207 to the standard drug regime resulted in a quicker conversion to negative sputum culture, with $48 \%$ of the patients receiving TMC207 having a negative culture at 8 weeks compared with $9 \%$ of those given placebo (hazard ratio $11.8,95 \%$ confidence interval 2.3 to $61.3 ; p=0.003$ ). Similar proportions of patients completed both courses with a similar side effects profile consistent with antituberculosis therapy; only nausea occurred significantly more frequently in the TMC207 group.

This study shows quicker conversion of sputum cultures in patients on the TMC207 regimen, highlighting its potential as antituberculous treatment in multidrug-resistant tuberculosis.

- Diacon AH, Pym A, Grobusch M, et al. The diarylquinoline TMC207 for multidrug-resistant tuberculosis. N Engl J Med 2009;360:2397-405.

\section{E Tevendale}

Correspondence to: Dr E Tevendale, CMT1, St James University Hospital, Leeds, UK; ewantevendale@nhs.net

Provenance and peer review: Commissioned; not externally peer reviewed.

Thorax 2009;64:1004. doi:10.1136/thx.2009.122887 